\title{
The Vessel Schedule Optimization Based on Particle Swarm Optimization Algorithm
}

\section{Xiang Chen ${ }^{1}$}

Key Laboratory of Maritime Dynamic Simulation and Control of Ministry of Transportation Dalian Maritime University, Dalian 116026, China

\section{Xinyu Zhang ${ }^{2}$}

Key Laboratory of Maritime Dynamic Simulation and Control of Ministry of Transportation Dalian Maritime University, Dalian 116026, China

Faculty of Infrastructure Engineering Dalian University of Technology, Dalian 116024, China

E-mail: zhang.xinyuesohu.com

\section{Tieshu Liu ${ }^{3}$}

The vessel traffic service of Tianjin Maritime Safety Administration, Tianjin 300457, China

\section{Jun Lin, Shun Yao}

Key Laboratory of Maritime Dynamic Simulation and Control of Ministry of Transportation Dalian Maritime University, Dalian 116026, China

\begin{abstract}
Marine transportation quality is largely affected by the port service level; however, the contextual inquiry shows that the vessel schedule is now a stage of manual schedule. The situation when the vessels gather inbound or outbound may cause port congestion, especially in some adverse weather. Based on the analysis of vessel schedule in the port, this paper proposes a mathematic model for vessel schedule in one-way fairway. In order to calculate the model, we design a code based on the particle position and use discrete particle swarm optimization (DPSO) algorithm to get the schedule order. The simulated test verifies that the algorithm is completely convergent in 150 generation and the maximum waiting time is 117 minutes. The result demonstrates that it can reduce the waiting time when compared with the "First-Come, First-Served" rules.
\end{abstract}

CENet2015

12-13 September 2015

Shanghai, China

${ }^{1}$ Speaker
${ }^{2}$ Corresponding Author

${ }^{3}$ This research was financially supported by National Natural Science Foundation of China (Grant No.: 51309043), Applied Basic Research of Ministry of Transport (Grant No.: 2014329225020), Fundamental Research Funds for the Central Universities (Grant No.: 3132014202), China Postdoctoral Science Foundation (Grant No.: 2014M551095), Outstanding Young Scholars Growth Plan of Liaoning Province (Grant No.: LJQ201405) and Liaoning Provincial Natural Science Foundation of China (Grant No.: 2014025005). 


\section{Introduction}

With the expansion of the port and the vessels' large-scale, how to increase the fairway utilization is now very critical under expansion of the channel condition. At present, the literature review focuses on three aspects:

(1) On the channel capacity: Jingxian Liu et al. used the mathematic statistics analysis method to study the ship arrival and department of Tianjin port as well as confirm that the regularity at main channels of Tianjin port conforms to the normal distribution [1]. At the same time, they use the queuing theory to forecast the capacity of Tianjin main channel to provide some advice to the port authority in order to expand the channel[2]. Taikun Huang et al. employed the SIMIO simulation software to simulate the capacity of Tianjin compound channel and assure the basis of channel expanding [3]. These researches thought from the port and engineering construction; but they didn't focus on the usage of the channel from the vessel aspect.

(2) On the channel usage efficiency: according to the distance of berth, size of vessel, type of ship and the draft, Guoyu Xu et al. employed the analytic hierarchy process to sort the vessel entering and leaving the one-way channel, the test in Kaohsiung port verified that the method had more advantages than the manual sort [4]; but the method was based on the specialist's experience, so the result may have some subjective factors.

(3) On the optimization of berth sources: researches on the berth optimization are various, especially on the allocation of container berth. Zhixiong Liu employed the particle swarm optimization and created the mathematic model to allocate the berth for container ship [5]. Lee adopted the heuristic algorithm to allocate the berth and the critical point is that they focus on minimizing the expense of the container ship in the port [6]. Jun Lin, gave a weight value to the scheduled vessels according to the schedule priority to, and adopted the genetic algorithm to solve the model [7]. Jintao Wang studied the Dayao bay of Dalian port to formulate the one-way fairway channel model and used the genetic algorithm to calculate the model [8]; however, both Jun Lin and Jintao Wang employed the genetic algorithm, but the convergent speed was slow and sometime could be convergent in local optimum. Peng et al. researched the archipelago berth allocation problem They thought draft, crane and restriction for different ships in the lane [9].

The paper is organized as follows: the problems and the model are described in Section 2. Next, the paper presents the DPSO method analysis, the simulated test and the results analysis in Section 3.The conclusion is made Section 4 at the end of the paper.

\section{Problem Description}

When numerous vessels gather inbound or outbound, the vessels can only queue to use the channel. At that time, the vessel traffic service officers (VTSO) may have an operation strategy to evacuate the vessels to diminish the ships' waiting time in port; however, the traditional schedule method employs the "First-Come, First-Served" (FCFS) rule, but it takes too much time for some vessels to wait for the channel as per this rule. On this basis, this paper aims at finding a related rational strategy to reduce the waiting time and accelerate the vessel's operational efficiency in port. The process is related to the arrival or departure time of the ship, mooring berth number, ship length, and the distance of the ship from anchorage to channel entrance etc.; but this problem is a non-liner integer problem. The ship is allowed to use the channel upon its arrival at the port or accomplishing the berth work. As a result, under the safety circumstance, the key point of the schedule is to make a reasonable and efficiency schedule order for the ship inbound or outbound.

\subsection{Model Assumption}

(1) The scheduled ship is ready in anchorage or berth when the schedule is started. 
(2) The fairway conditions (like draft and visibility etc.) may meet the demand of all ships.

(3) The berth satisfies the requirement of the mooring ship.

(4) The pilot, tug boat and other auxiliary equipment may meet the vessel demand.

\subsection{Mathematic Model}

Objective function:

$$
\text { Minimize: } \sum_{i=1}^{n}\left(L_{i}-A_{i}\right) \text {; }
$$

subject to:

$$
\begin{aligned}
& s_{i}=t s_{i} * x_{i j}+\left(1-x_{i}\right) * t s 1_{i}+\frac{I O_{i} * x_{i j} * d_{i}}{v_{i}}+\frac{\left(1-I O_{i}\right) * l e n_{i}}{v_{i}} ; i \in V, j \in B \\
& s 1_{i}=s_{i}+\frac{c l}{v_{i}} ; i \in V \\
& w_{i}=s 1_{i}+\frac{I O_{i} * l e n_{i}}{v_{i}}+o_{i} ; i \in V \\
& s 2_{i}=w_{i}+\left(1-I O_{i}\right) *\left(1-x_{i}\right) * A_{i} ; i \in V \\
& L_{i}=\left(1-I O_{i}\right) * s 1_{i} ; i \in V \\
& \operatorname{tgap} 0=\frac{6 * v \operatorname{len}_{i}}{v_{i-1}} ; i \in V \\
& \operatorname{tgap} 1=\frac{6 * \max \left(\text { vlen }_{i}, \text { vlen }_{i-1}\right)}{v_{i-1}} ; i \in V \\
& \left\{\begin{array}{l}
s_{i}>s_{i-1}+\operatorname{tgap} 0+x_{i} * M ; i \in V \\
v_{i} \leqslant v_{i-1} ; i \in V
\end{array}\right. \\
& s 1_{i-1}+\operatorname{tgap} 1 \leqslant s_{i} ; i \in V \\
& w_{i}+\operatorname{tgap} 1<t s 1_{i}+\frac{\operatorname{len}_{i}-\operatorname{len}_{i-1}}{v_{i}} ; i \in V \\
& s 1_{i}+\frac{\operatorname{len}_{i}}{v_{i-1}}+\operatorname{tgap} 1<t s 1_{i} ; i \in V \\
& \left\{\begin{array}{c}
t s_{i}-x_{i j} * A_{i} \leqslant E ; L_{i}-A_{i} \geqslant 0 \\
t s 1_{i}-\left(1-x_{i j}\right) * A_{i} \leqslant E ; i \in V, j \in B
\end{array}\right.
\end{aligned}
$$

The notation used in this paper is summarized as follows: Indices: 
$i=(1,2, \ldots, n) \in V \quad$, Set of ships;

$j=(1,2, \ldots, n) \in B \quad$, Set of berths;

Decision variable:

$I O_{i}=\left\{\begin{array}{l}1, \text { the ship inbound } ; \\ 0, \text { the ship outbound } .\end{array}\right.$

$x_{i j}=\left\{\begin{array}{l}1, \text { if ship is served at berth } j ; \\ 0, \text { otherwise. }\end{array}\right.$

Parameters:

$A_{i}$ : Arrival time of ship i;

$L_{i}$ : Departure time of ship i;

$t s_{i}$ : Start schedule time of ship $i$ in anchorage;

$t s 1_{i}$ : Start schedule time of ship i in berth;

$d_{i}$ : Distance of ship i from anchorage to channel entrance;

$v_{i}$ : Speed of ship $i$ in the fairway;

$c l$ : Length of the fairway;

$l e n_{i}$ : Distance of ship i from the channel end to berth;

$v$ len $_{i}$ : Length of ship i;

$s_{i}$ : Time of ship i entering the channel;

$s 1_{i}$ : Time of ship i leaving the channel;

$w_{i}$ : Work time of ship i in the berth;

$s 2_{i}$ : Time of the ship work over to depart the berth or the ship is in berth to outbound;

tgap0 : Safety interval time of the ship at the same direction;

tgap1 : Safety interval time of the ship in the contrary direction;

The objective function(2.1) indicates minimizing the work time in the port; the constraints (2.2) (2.6) express that the time of ship i enters the channel, leaves the channel and port time; The constraints (2.7) and (2.8) are the interval time of the ship at the same direction or contrary direction to make sure safety between the two vessels; Equation (2.9) is the constraint of the two ships before or after inbound; at the same time, (2.10) refers that the outbound ship is earlier than the inbound ship; the constraint (2.11) refers that leaving channel time of inbound ship is earlier than entering the channel time of outbound ship; the constraint (2.12) means that the time of outbound is earlier than inbound ship; the constraint (2.13) represents that the limit time of ship can't be over and the schedule start time is later than the arrival time of ship.

\section{Design Algorithm}

\subsection{Discrete Particle Swarm Optimization Algorithm}

The particle swarm optimization algorithm proposed by James Kennedy and Russell Eberhard in 1995. The problem of the paper is a nonnumeric problem in discrete space. To solve the problem, the key is that how to use the particle to map the schedule problem of the paper. We adopt a method based on the particle position with inertia weight [10] of DPSO method.

The velocity update equation is given by:

$$
v_{i}(t+1)=w * v_{i}(t)+c_{1} * r_{1} *\left[p_{i}(t)-x_{i}(t)\right]+c_{2} * r_{2} *\left[p_{g}(t)-x_{i}(t)\right]
$$

The position update equation is given by:

$$
x_{i}(t+1)=x_{i}(t)+v_{i}(t+1), i=1,2, \ldots, n .
$$

The method based on Particle [11] is: if there are $\mathrm{n}$ ships for schedule, the first dimension uses the natural number to represent the number of $n$ ships. The second dimension uses the position vector to represent the good or bad of the particle. For example, if there are five vessels for schedule, we use number 1, 2, 3, 4 and 5 to represent the vessel. When the algorithm iterates, the vector position of these particles may become different; in this sense, we can sort the 
sequence by the vector position of these particles, and that we can get a reasonable schedule scheme, as shown in Fig.1, from which, we get a reasonable schedule sequence: $\left[\begin{array}{lllll}1 & 4 & 2 & 5 & 3\end{array}\right]$.

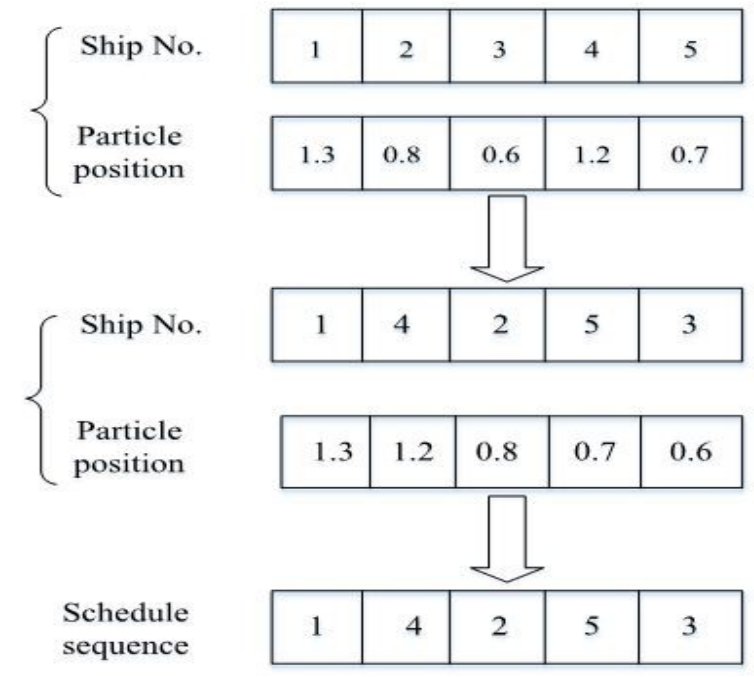

Figure1: Example of A Scheduled Sequence

\subsection{Simulate Test}

We adopt the simulated data to verify the model. The limit time of waiting $\mathrm{E}$ is 3 hours. As the ship schedule work is a continuous process, we must link the last stage with the time. The ship status at the last time is as shown in Table 1.

\begin{tabular}{|l|l|l|l|l|l|l|l|}
\hline Ship number & $\begin{array}{l}\text { Length( } \\
\mathrm{m})\end{array}$ & $\begin{array}{l}\text { Directi } \\
\text { on }\end{array}$ & $\begin{array}{l}\text { Speed( } \\
\mathrm{kn})\end{array}$ & $\begin{array}{l}\text { Berth } \\
\text { number }\end{array}$ & $\begin{array}{l}\text { Start } \\
\text { time }\end{array}$ & $\begin{array}{l}\text { Channel } \\
\text { length }\end{array}$ & $\begin{array}{l}\text { Distance from berth to } \\
\text { channel (n mile) }\end{array}$ \\
\hline 0 & 145.1 & Out & 11 & $3^{\#}$ & $08: 55$ & 6 & 0.7 \\
\hline
\end{tabular}

Table 1: Ship Status at the Last Time

In the schedule process, some vessels may be outbound and some ships may enter in the port. The initial berth status is shown in table 2 .

\begin{tabular}{|l|l|l|l|l|l|l|l|l|l|l|l|}
\hline Berth & $1^{\#}$ & $2^{\#}$ & $3^{\#}$ & $4^{\#}$ & $5^{\#}$ & $6^{\#}$ & $7^{\#}$ & $8^{\#}$ & $9^{\#}$ & $10^{\#}$ & $11^{\#}$ \\
\hline status & free & busy & free & busy & free & busy & busy & busy & busy & free & free \\
\hline
\end{tabular}

Table 2: Initial Berth Status 4.

The information of the scheduled ship is shown in Table 5 and the result is shown in Table 


\begin{tabular}{|c|c|c|c|c|c|c|c|c|}
\hline $\begin{array}{c}\text { Ship } \\
\text { number }\end{array}$ & $\begin{array}{c}\text { Lengt } \\
\mathrm{h}(\mathrm{m})\end{array}$ & $\begin{array}{c}\text { Direct } \\
\text { ion }\end{array}$ & $\begin{array}{c}\text { Speed } \\
(\mathrm{kn})\end{array}$ & $\begin{array}{c}\text { Berth } \\
\text { number }\end{array}$ & $\begin{array}{c}\text { Start } \\
\text { time }\end{array}$ & $\begin{array}{c}\text { Channel } \\
\text { length }\end{array}$ & $\begin{array}{c}\text { Distance from } \\
\text { berth to channel(n } \\
\text { mile) }\end{array}$ & $\begin{array}{c}\text { Distance from } \\
\text { anchorage to } \\
\text { channel(n mile) }\end{array}$ \\
\hline 1 & 148 & In & 5.3 & - & $09: 09$ & 6 & 0.7 & 8 \\
\hline 2 & 130 & Out & 7.1 & $2^{\#}$ & $09: 11$ & 6 & 2.1 & - \\
\hline 3 & 278.8 & In & 5.5 & - & $09: 31$ & 6 & 1.8 & 6 \\
\hline 4 & 142.7 & In & 7.6 & - & $09: 24$ & 6 & 0.9 & 6 \\
\hline 5 & 166.2 & In & 8.2 & - & $09: 15$ & 6 & 1.1 & 6 \\
\hline 6 & 97.2 & In & 6.3 & - & $09: 29$ & 6 & 1.7 & - \\
\hline 7 & 72 & In & 6.4 & - & $09: 03$ & 6 & 0.6 & - \\
\hline 8 & 147.5 & Out & 7.2 & $6^{\#}$ & $09: 33$ & 6 & 1.5 & - \\
\hline 9 & 150.4 & Out & 10.3 & $7^{\#}$ & $09: 30$ & 6 & 1.0 & 8 \\
\hline 10 & 115.8 & Out & 7.4 & $9^{\#}$ & $09: 35$ & 6 & 1.3 & - \\
\hline 11 & 89.2 & In & 5.9 & - & $09: 30$ & 6 & 2.3 & 6 \\
\hline 12 & 95.2 & Out & 4.8 & $4^{\#}$ & $09: 17$ & 6 & 1.6 & 8 \\
\hline 13 & 144.8 & In & 6.0 & - & $09: 23$ & 6 & 2.8 & - \\
\hline 14 & 52.8 & In & 5.8 & - & $09: 02$ & 6 & 3.3 & \\
\hline 15 & 241.3 & out & 4.7 & $8^{\#}$ & $09: 17$ & 6 & 0.6 & \\
\hline
\end{tabular}

Table 3: Information before Scheduling

\begin{tabular}{|c|c|c|c|c|c|c|c|c|c|}
\hline $\begin{array}{c}\text { Ship } \\
\text { numb } \\
\mathrm{er}\end{array}$ & $\begin{array}{c}\text { Directio } \\
\mathrm{n}\end{array}$ & $\begin{array}{c}\text { Speed( } \\
\mathrm{kn})\end{array}$ & $\begin{array}{c}\text { The } \\
\text { fitness } \\
\text { value }\end{array}$ & $\begin{array}{c}\text { Berth } \\
\text { numbe } \\
\mathrm{r}\end{array}$ & $\begin{array}{c}\text { Start } \\
\text { time } \\
(\mathrm{min})\end{array}$ & $\begin{array}{c}\text { Actual } \\
\text { start time } \\
(\mathrm{min})\end{array}$ & $\begin{array}{c}\text { Enter the } \\
\text { channel } \\
\text { time(min) }\end{array}$ & $\begin{array}{c}\text { Finish the } \\
\text { schedule } \\
\text { time(min) }\end{array}$ & $\begin{array}{c}\text { Waiting } \\
\text { time(min } \\
)\end{array}$ \\
\hline 2 & Out & 7 & 0.972 & - & $09: 11$ & $09: 11$ & $09: 18$ & $09: 30$ & 0 \\
\hline 12 & Out & 4.8 & 0.965 & - & $09: 17$ & $09: 17$ & $09: 23$ & $09: 45$ & 0 \\
\hline 15 & Out & 4.7 & 0.961 & - & $09: 17$ & $09: 28$ & $09: 35$ & $09: 58$ & 11 \\
\hline 9 & Out & 10.3 & 0.959 & - & $09: 30$ & $09: 37$ & $09: 43$ & $10: 22$ & 7 \\
\hline 8 & Out & 7.2 & 0.956 & - & $09: 33$ & $09: 46$ & $09: 54$ & $10: 33$ & 13 \\
\hline 10 & Out & 7.4 & 0.953 & - & $09: 35$ & $09: 56$ & $10: 08$ & $10: 42$ & 21 \\
\hline 14 & In & 5.8 & 0.902 & $3^{\#}$ & $09: 02$ & $10: 05$ & $10: 15$ & $10: 48$ & 63 \\
\hline 1 & In & 5.3 & 0.900 & $1^{\#}$ & $09: 09$ & $10: 15$ & $10: 21$ & $10: 57$ & 66 \\
\hline 7 & In & 6.4 & 0.876 & $10^{\#}$ & $09: 03$ & $10: 27$ & $10: 34$ & $11: 12$ & 84 \\
\hline 5 & In & 8.2 & 0.832 & $5^{\#}$ & $09: 15$ & $10: 36$ & $10: 46$ & $11: 28$ & 81 \\
\hline 4 & In & 7.6 & 0.797 & $2^{\#}$ & $09: 24$ & $10: 44$ & $10: 52$ & $11: 35$ & 80 \\
\hline 13 & In & 6.0 & 0.731 & $8^{\#}$ & $09: 23$ & $10: 51$ & $11: 00$ & $11: 42$ & 88 \\
\hline 6 & In & 6.3 & 0.625 & $11^{\#}$ & $09: 29$ & $11: 02$ & $11: 10$ & $11: 55$ & 93 \\
\hline 3 & In & 5.5 & 0.603 & $4^{\#}$ & $09: 31$ & $11: 13$ & $11: 20$ & $12: 08$ & 102 \\
\hline 11 & In & 5.9 & 0.565 & $7^{\#}$ & $09: 30$ & $11: 27$ & $11: 36$ & $12: 25$ & 117 \\
\hline
\end{tabular}

Table 4: Information after Scheduling

\begin{tabular}{|c|c|c|c|}
\hline Comparison item & Schedule order & $\begin{array}{l}\text { The maximum } \\
\text { Waiting time }(\mathrm{min})\end{array}$ & $\begin{array}{l}\text { The whole waiting } \\
\text { time(min) }\end{array}$ \\
\hline FCFS & $\begin{array}{llllllllllll}14 & 7 & 1 & 2 & 5 & 12 & 15 & 13 & 4 & 6 & 9 & 11 \\
3 & 8 & 10 & & & & & & & & & \\
\end{array}$ & 235 & 1025 \\
\hline PSO schedule & $\begin{array}{llllllllllll}2 & 12 & 15 & 9 & 8 & 10 & 14 & 1 & 7 & 5 & 4 & 13 \\
6 & 3 & 11 & & & & & & & & & \\
\end{array}$ & 117 & 82 \\
\hline
\end{tabular}

Table 5: Compare FCFS with PSO Schedule Algorithm

The result demonstrated in Table 4 shows that vessels adhere to "First-Out, Last-In" principle. As to the two ships that are alongside the same berth, the "First-out, Last-in" principle can offset the conflict between the two ships, which can improve the efficiency of using the berth. For example, No. 2 ship is alongside Berth $2^{\#}$, then No. 2 ship can has the priority to outbound. And then, No. 4 ship will be alongside in Berth $2^{\#}$. In general, the ships in anchorage spend more time than those in berth. Compared with the FCFS rule, the maximum waiting time of the PSO schedule is less than the FCFS. At the same time, the whole waiting time reduces 199 minutes. Form the whole process, the last vessel to be scheduled needs 117 minutes, no more than the limit time of 180 minutes. From the algorithm efficiency as shown in Fig. 2, the 
iteration is 300 generations and the algorithm is convergent in the fifth generation. While the algorithm runs in 150 generation, the algorithm is completely convergent.

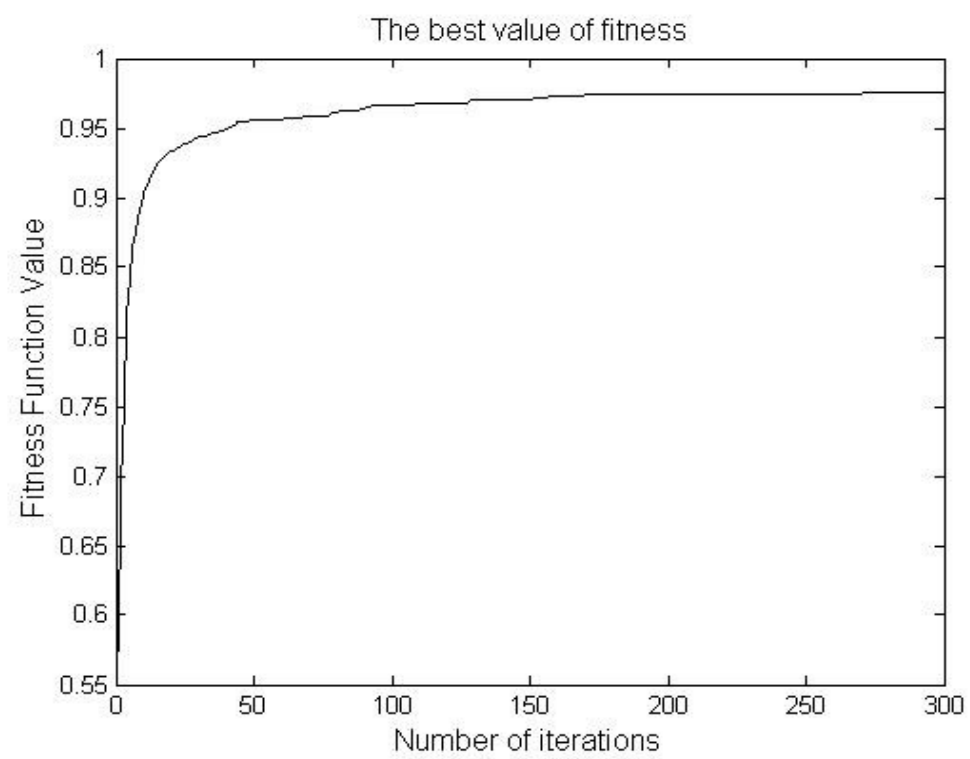

Figure 2: Performance of the Calculation Iteration

\section{Conclusion}

This paper proposes a schedule mathematic model for one-way fairway and uses the DPSO algorithm based on the position of particle to calculate the result. It can reduce time of vessels in the port and enhance efficiency of the port; however, the model of the paper may be relatively ideal, which overlooks some requirements in the real operation in the port, such as the speed of ships in the channel and the real situation that the ship's speed is slowly decreased or increased when the ship is inbound or outbound, but we employ the average speed to replace it. In this sense, the model is worth of further research to make it to correspond to the reality.

\section{References}

[1] Jingxian Liu, Yunbin Li. Distribution regularity analysis of ship arrival and department at Tianjin Port main channel [J]. Journal of Wuhan University of Technology, vol.32 (2), pp352353(2008) (In Chinese).

[2] JIngxian Liu, Xiaobao Han, Xiangping Yi. Capacity analysis of restricted channels based on the queuing theory [J]. Navigation of China, vol.31 (3), pp261-264(2008) (In Chinese).

[3] Taikun Huang, Yuanzhan Wang, Shaowu LI. Dynamic system simulation on throughput capacity of compound channel of sea port [J]. Journal of Dalian Maritime University, vol.41 (1), pp2026(2015) (In Chinese).

[4] Guoyu Xu, Tucheng Guo, Zhaolin Wu. Optimum scheduling model for ship in/outbound harbor in one-way traffic fairway [J]. Journal of Dalian Maritime University, vol.34 (4), pp150-153(2008) (In Chinese).

[5] Zhixiong Liu. Particle swarm optimization algorithm for port berth scheduling problem [J]. Logistics engineering and management, vol.32 (8), pp101-103(2010) (In Chinese).

[6] Yusin Lee, Chuen-Yih Chen. An optimization heuristic for the berth scheduling problem [J]. European Journal of Operational Research, vol.196 (5), pp500-508(2009). 
[7] Jun Lin, Xinyu Zhang, Shun Yao, Xin Xiong. Optimization of ship scheduling based on one-way fairway [J]. Algorithm and Architectures for Parallel Processing Lecture Notes in Computer Science, vol.8631 (192), pp479-486(2014) (In Chinese).

[8] Jintao Wang. Research on vessels scheduling model and algorithm based on one-way channel [D]. Dalian: The degree of Master of Engineering in Dalian Maritime University (2014) (In Chinese).

[9] Jiangliang Peng, Renjian Li. A discrete particle swarm optimization algorithm for archipelago berth allocation problem [J]. Journal of Computer, vol.9 (7), pp1648-1656(2014).

[10] Dingwei Wang, Junwei Wang, Hongfeng Wang. Intelligent Optimization Methods [M].Beijing: Higher Education Press, pp.217-218(2007) (In Chinese).

[11] Zhixiong Liu. Research and Application of Particle Swarm Optimization in Scheduling Problem [D].Wuhan: Doctor Dissertation of Wuhan University of Technology (2005) (In Chinese). 